\title{
Para além dos indicadores de avaliação da produção intelectual na grande área da saúde
}

Yara M. Carvalho* Edison de Jesus Manoel **

\begin{abstract}
Resumo: O presente artigo expressa as reflexões que vimos desenvolvendo a respeito dos indicadores de produção intelectual da comunidade científica brasileira, com atenção especial ao livro. Como pesquisadores credenciados em Programa de Pós-graduação em Educação Física, vinculada à Área 21 na Grande Área da Saúde, privilegiamos aqui o debate relativo às características, limites e possibilidades dos indicadores para a apreciação qualitativa da produção intelectual, em particular para aquela veiculada pelas Ciências Humanas e Sociais no campo da saúde, para este caso, as subáreas sociocultural e pedagógica da Educação Física.

Palavras-chave: Indicadores de produção científica. Livros. Sistemas de créditos e avaliação de pesquisadores. Bibliometria.
\end{abstract}

\section{INTRODUÇÃO}

No âmbito da pós-graduação o debate sobre os indicadores de avaliação da produção intelectual acontece com a instituição do QUALIS, um instrumento para auxiliar na caracterização da qualidade da produção intelectual na avaliação dos programas de pós-graduação promovida pela CAPES (SOUZA, 2002). Ocorre que esse instrumento foi sistematizado de modo a ter o periódico científico como sua principal referência, logo a produção intelectual valorizada é o artigo científico, e, conseqüentemente, a avaliação de um Programa é definida pelo artigo.

* Doutora em Saúde Coletiva pela Faculdade de Ciências Médicas da Unicamp, Campinas. Docente do Programa de Pós-Graduação em Educação Física - USP. : E-mail yaramc@usp.br.

** Doutor em Psicologia pela Universidade de Sheffield, Inglaterra. Docente do Programa de Pós-Graduação em Educação Física - USP

Movimento, Porto Alegre, v.12, n. 03, p. 193-225, setembro/dezembro de 2006. 
Da implementação do QUALIS, em 1998, até nossos dias há uma crescente influência desse instrumento a ponto de exercer hoje papel central nos rumos da produção científica das áreas (BONINI, 2004). E uma das conseqüências mais imediatas desse movimento foi a atribuição de um papel secundário ao livro. Ainda que se reconheça a necessidade de avaliar o livro, as iniciativas nessa direção sempre foram tímidas diante das supostas dificuldades para gerar critérios objetivos, como se os critérios para avaliar a produção na forma de artigo fossem desprovidos de controvérsias.

Não só concordamos com a idéia de que o livro precisa ser avaliado como ao longo dos últimos meses vimos trabalhando ${ }^{1}$ para apresentar uma proposta de avaliação para o livro de modo a garantir a análise quantitativa e qualitativa e, ao mesmo tempo, considerar o livro um indicador no conjunto da avaliação da produção intelectual.

Nossa proposição resulta de leituras e das experiências construídas no convívio entre áreas como Educação Física, Saúde Coletiva, Fisioterapia, Enfermagem e Fonoaudiologia, na Grande Área da Saúde, fronteiras que tradicionalmente não atribuem ao

\footnotetext{
1 Em outubro de 2004 foi constituída a comissão designada "QUALIS livro" pelo Fórum Nacional de Pós-Graduação em Educação Física, Fonoaudiologia, Fisioterapia e Terapia Ocupacional, composta inicialmente pelos docentes Beatriz C. Novaes, Edison de J. Manoe e Rinaldo J. Guirro e, a partir de março de 2005 com Yara M Carvalho, responsáveis pela produção de um documento propositivo contendo princípios e critérios para avaliação do livro. Entre outubro de 2004 e março de 2005 a comissão consultou a comunidade pedindo sugestões para a avaliação do livro. Em junho de 2005 a primeira versão é apresentada na reunião do Fórum que aconteceu no Rio de Janeiro e no dia 4 de maio de 2006 o documento foi apresentado e aprovado em reunião do Fórum, em Brasília e entregue documento fol apresentado e aprovado em reunia do Forum, em Brasilia, e entregue para a nosso representante de área na CAPES, o professor Eduardo Kokubun que, por sua vez, encaminhou o documento para apreciação do Diretor de Avaliação da CAPES, o professor Renato Janine Ribeiro. Em agosto de 2006, o documento foi aprovado pela CAPES e a comissão foi chamada para desenvolver o primeiro exercício de avaliação do livro por ocasião da avaliação de acompanhamento dos programas de pós-graduação para o período referente a 2005, ou seja, avaliamos os livros publicados pela Área 21 (Fonoaudiologia, Fisioterapia, Terapia Ocupacional e Educação Física) no ano de 2005 Desse trabalho foi sistematizado um relatório, incorporado ao documento de área, que subsidiou a avaliação da produção intelectual durante a avaliação de acompanhamento - 2006.
}

Movimento, Porto Alegre, v.12, n. 03, p. 193-225, setembro/dezembro de 2006. 
livro protagonismo ainda que a formação em saúde seja conduzida por ele. Assim, parte de nossa reflexão situa-se nesse contexto, todavia, não nos restringiremos a ele posto que o livro ainda carece de maior atenção na avaliação da pós-graduação, mas, sobretudo, na política científica brasileira.

Nesse sentido, a natureza do livro e os critérios para sua avaliação precisam necessariamente estar desvinculados da lógica da avaliação do artigo, de um lado, e, de outro, o processo de avaliação do livro não pode estar dissociado da idéia de um indicador que remete a dados quantitativos comprometidos com os qualitativos. Mais adiante desenvolveremos demoradamente esta idéia, mas o que importa destacar desde já é que a discussão da avaliação e dos indicadores, de modo geral, remete a duas questões: a) a da política de divulgação científica brasileira; b) e, a das formas pelas quais a comunidade cientifica se apropria dos canais de comunicação que divulgam sua produção, que a seguir serão desenvolvidas.

\section{APOLIITICA DE DIVULGAÇÃO CIENTÍFICA BRASILEIRA}

O debate a respeito da política de divulgação científica brasileira cada vez mais avança devido, entre outros motivos, ao protagonismo das agências de fomento, de algumas editoras universitárias, da Sociedade Brasileira para o Progresso da Ciência (SBPC), de alguns periódicos e de algumas categorias profissionais, especialmente os jornalistas e editores científicos. No âmbito institucional, em abril de 2006 aconteceu no Brasil o 1o Congresso Brasileiro de Informação e Documentação Esportiva em Brasília que reuniu pesquisadores de vários países com vistas a debaterem a respeito das redes internacionais de informação e documentação científica, das bibliotecas e publicações técnicas e científicas e de uma política brasileira de informação e documentação, entre outros temas. Em agosto de 2006, o Colégio Brasileiro de Ciências do Esporte (CBCE) constituiu o Fórum Nacional Permanente de Pós-Graduação em Educação Física que reuniu a

Movimento, Porto Alegre, v.12, n. 03, p. 193-225, setembro/dezembro de 2006. 
maioria dos coordenadores dos programas de pós-graduação em Educação Física, professores, pesquisadores e estudantes que gerou um documento ${ }^{2}$ posteriormente enviado para a o CNPq, CAPES, FINEP, SBPC, Fórum da Área 21 e programas de pós-graduação que aponta novos rumos para a construção de uma política científica mais sintonizada com interesses e necessidades do conjunto dos pesquisadores que fazem a pós-graduação em Educação Física do país e, mais recentemente, na $58^{\mathrm{a}}$ Reunião Anual da SBPC que aconteceu em julho de 2006, em Florianópolis, o $\mathrm{CBCE}^{3}$ constituiu um Fórum Permanente de Editores Científicos em Educação Física com intuito de agregar e sistematizar o debate relativo à política editorial no campo específico.

Esse é um tema que mobiliza governos, associações científicas e organismos internacionais, no sentido de apoiar encontros, troca de informações, conhecimento e tecnologia (Ministério de Ciência e Tecnologia, Ministério da Saúde) e não é uma preocupação recente, já acumula décadas. $\mathrm{O}$ aumento do número de cientistas, do volume de conhecimentos e da quantidade de publicações, a partir da Segunda Guerra Mundial, aliados à finitude dos recursos financeiros, provocou a necessidade de se constituir metodologias de avaliação com vistas a qualificar e hierarquizar o investimento em pesquisa cientifica. E, nos últimos anos, tem sido crescente o interesse de especialistas e autoridades governamentais brasileiras pelo estabelecimento de indicadores quantitativos de medição da produção científica porque eles auxiliam no entendimento da dinâmica de C\&T, como instrumento para o planejamento de políticas e tomada de decisões neste setor. Nesse nível de valoração, a tomada de decisões em C\&T tornou-se um pro-

${ }^{2} \mathrm{O}$ documento está disponível no portal do Colégio Brasileiro de Ciências do Esporte www.cbce.org.br , assim como mais detalhes a respeito do Fórum Nacional Permanente de Pós-Graduação em Educação Física.

${ }^{3} \mathrm{O}$ Colégio Brasileiro de Ciências do Esporte é uma entidade científica que agrega pesquisadores de várias origens de formação no campo da Educação Física-Ciências do Esporte. Para conhecer mais visite o portal www.cbce.org.br

Movimento, Porto Alegre, v.12, n. 03, p. 193-225, setembro/dezembro de 2006. 
cesso complexo e contencioso, solucionado a partir de mecanismos simplificadores dessa tarefa, os indicadores científicos.

Outro acontecimento importante, nesse período, que ocorreu paralelamente foi o início dos estudos sociais da ciência, tanto de natureza teórica quanto empírica. Estes estudos constituem um campo interdisciplinar da ciência que agrega uma ampla gama de interesses e perspectivas intelectuais, entre os quais se pode mencionar três vertentes: a sociologia do conhecimento; os estudos de laboratório, da atividade científica; e, a constituição da Cienciometria, que envolve análises quantitativas da produção científica (Robert K. Merton, Derek J. de Solla Price e Eugene Garfield)..

Os indicadores científicos desempenham um papel crucial na política científica à medida que eles sintetizariam o processo intrincado que envolve o conhecimento científico. Pela própria complexidade do processo, os indicadores serviriam a duas funções: levantar subsídios para a tomada de decisão (de modo simplificado, vale dizer, posto que uma longa cadeia de processos é captada em único indicador) e apontar para a comunidade o que é mais significativo na atividade científica. Um dos perigos do uso dos indicadores é a relação direta que se estabelece entre eles e a avaliação propriamente dita. Os indicadores subsidiam a tomada de decisão sobre o estado de determinado sistema, todavia, eles não são o sistema. A não observância dessa distinção leva muitas vezes a uma confusão entre meios e fins.

Os desafios na construção de indicadores residem na dificuldade de garantir que a simplificação não implique em visões estreitas da produção. De fato, a produção intelectual é diversa e construir indicadores capazes de abarcar tal diversidade é essencial. Um trabalho realizado pela Comissão Especial de Regime de Trabalho da Universidade de São Paulo, em decorrência da avaliação institucional ocorrida entre 1996 e 2001, identificou que a publicação de artigos em periódicos científicos é um indicador

Movimento, Porto Alegre, v.12, n. 03, p. 193-225, setembro/dezembro de 2006. 
dentre 11 identificados para caracterizar a produção intelectual. Nessa temática, um dos pontos de maior controvérsia surge em decorrência das diferenças entre as ciências naturais e as ciências sociais e humanas. As tradições e culturas particulares a cada ciência jogam a favor das divergências na consideração do que é produção intelectual em cada uma delas gerando uma tensão bem conhecida desde que Snow cunhou o termo "as duas culturas" (SNOW, 1995).

A hegemonia de uma das culturas, a das ciências naturais, no gerenciamento dos sistemas de pesquisa e pós-graduação tem levado a um viés na elaboração de indicadores. Em decorrência, membros da outra cultura, a das ciências sociais e humanas, ou desprezam a política científica ou abandonam suas convicções para adequar sua produção ao modelo vigente de modo a atender o que aponta os indicadores. Em ambos os casos, as conseqüências para a promoção, qualificação e avanço do conhecimento científico não são alentadoras.

\section{AS FORMAS PELAS QUAIS A COMUNIDADE CIENTIFICA SE APROPRIA DOS CANAIS DE COMUNICAÇÃO}

A ciência é um empreendimento coletivo e a comunicação de idéias detém papel crucial. A comunicação é uma estratégia para que o pesquisador possa valorar o conhecimento por ele produzido por meio de credenciamento externo (CHRISTENSON, J.; SIGELMAN, L., 1985). Cada área científica é regida por uma cultura e cada uma dessas culturas define a forma de comunicação que dá ao conhecimento esse credenciamento.

Nas ciências naturais, predomina a comunicação por meio dos artigos em periódicos científicos. E como todo veículo de comunicação ele possui regras que, por sua vez, condiciona a um tipo de comunicação enxuta e veloz com intuito de atingir a comunidade rapidamente e a resposta da comunidade é igualmente instantânea. Assim, um artigo, salvo exceção, tem em média uma vida útil de até cinco anos - representada pela curva de citações

Movimento, Porto Alegre, v.12, n. 03, p. 193-225, setembro/dezembro de 2006. 
do artigo em outros trabalhos, com um pico de citações logo após a divulgação seguida de uma gradual diminuição.

Nesse canal de comunicação, os pesquisadores estão interessados no que é imediato, a ênfase reside nas informações mais recentes, nos achados que denotam novidade. Não é raro encontrar periódicos cuja exigência para análise de manuscritos seja citações que façam referência a artigos publicados apenas nos últimos cinco anos ${ }^{4}$. Nessa dinâmica, o trabalho mais importante é o que saiu publicado na semana passada, ou ainda o que sairá publicado na semana que vem. $\mathrm{O}$ acesso às informações mais recentes e a velocidade com que se chega a elas se transforma em diferencial para o sucesso de um pesquisador ou grupo de pesquisadores. A viabilização de periódicos on line vem ao encontro desse anseio por informação recente e de rápido acesso.

Se esses canais de comunicação fazem sentido diante da forma como as ciências naturais operam, não podemos deixar de mencionar que do ponto de vista da formação de recursos humanos um dos perigos dessa lógica é que o estudante de iniciação científica, de mestrado e de doutorado muitas vezes se fixa nesse tipo de referência e perde a noção, a história e a dimensão do campo. As conseqüências são perceptíveis na qualidade das investigações e no grau de autonomia intelectual dos pesquisadores, ainda que em levantamento bibliográfico junto às disciplinas dos programas de pósgraduação da Área 21 durante o triênio 2001-2003 e durante o ano de 2004, tenhamos encontrado presença quase que absoluta de livros e capítulos de livro ${ }^{5}$ em detrimento de artigos.

${ }^{4}$ Há um outro motivo para a utilização desse critério que vale destacar: editores ansiosos por indexarem ou manterem seus periódicos em bases de dados como a do ISI, por exemplo, impóm essa exigencia posto que o fator de impacto é determinado, entre outros itens, pela idade dos artigos citados, quanto mais recentes os artigos, maior é o fator de
impacto.

Durante o ano de 2005 realizamos exaustiva pesquisa relativa ao tipo de produção recomendada nas disciplinas dos programas de pós-graduação na Área 21 e, em especial, na Educação Física, e constatamos que a produção que teoricamente forma o pesquisador é veiculada no formato de livro. Dados detalhados desse trabalho serão apresentados mais adiante.

Movimento, Porto Alegre, v.12, n. 03, p. 193-225, setembro/dezembro de 2006. 
Aparte da hegemonia do periódico, como canal de comunicação científica, o desenvolvimento tecnológico é, cada vez mais, valorizado e as patentes são a expressão dessa importância à medida que se transformam em novo indicador da produção. E aqui também é necessário qualificar a produção, é preciso distinguir entre o depósito de uma patente e o seu licenciamento. No primeiro caso, o pesquisador entende que determinado produto deve ser patenteado porque poderá ter grande utilidade no futuro, fato que não necessariamente se concretizará. No segundo caso, já há reconhecimento do produto à medida que ele passa a ser alvo de utilização pela sociedade.

Voltando ao livro, o seu espaço é reduzido nas ciências naturais e, na maioria dos casos, se constituem em coletâneas com capítulos que sintetizam as pesquisas experimentais do docente ou de uma linha de investigação. Livros de único autor são raros, podem ser exemplos os autobiográficos, escritos que sintetizam o trabalho de uma vida, de pesquisadores com reconhecida influência na área.

Nas ciências sociais e humanas os meios de comunicação da produção estão centrados, tradicionalmente, nos livros. Nessa cultura o livro é o veículo mais apropriado, pois ele, por natureza, instiga à reflexão, seja por meio da interpretação ou explicação, ao propor questões teórico-conceituais e metodológicas que subsidiam novas idéias, pesquisas, ou ainda remete à análise crítica acerca de um tema ou área de investigação. Por tudo isso o livro pode determinar um tempo de impacto mais lento.

Eduardo Giannetti (1998) constrói um paralelo entre os dois veículos, o artigo e o livro como meios de comunicação, que nos ajuda a entender melhor a natureza de cada um, em particular do livro:

A leitura é a ocasião de um encontro. Quando o teor do trabalho é predominantemente técnico ou factual, os termos de troca entre autor e

Movimento, Porto Alegre, v.12, n. 03, p. 193-225, setembro/dezembro de 2006. 
leitor tendem a ser claros e bem definidos: o que um oferece e o outro busca na leitura são informações relevantes e ferramentas para a obtenção de novos resultados. O contato entre as mentes é de superficie e o grau de assimilação dos conteúdos é mensurável.

\section{[...]}

Mas quando se trata de um texto literário ou filosófico de conteúdo essencialmente reflexivo, a natureza da relação mediada pela palavra impressa é outra. Mais que uma simples troca intelectual entre autor e leitor, a leitura é o enredo de dois solilóquios silenciosos e separados no tempo: o diálogo interno do autor com ele mesmo enquanto concebe e escreve o que lhe vai pela mente absorta; e o diálogo interno do leitor consigo próprio enquanto lê, interpreta, assimila e recorda o que leu.

\section{$[\ldots]$}

Ler é recriar. A palavra final não é dada por quem a escreve, mas por quem a lê. $O$ diálogo interno do autor é a semente que frutifica (ou definha) no diálogo interno do leitor. A aposta é reciproca, o resultado imprevisivel. Entendimento absoluto não há.

'Autores são atores, livros são teatros'. A verdadeira trama é a que transcorre na mente do leitor-interlocutor. A ocasião da leitura, não menos que a da criação literária, pode ser o momento para um encontro sereno, amistoso concentrado - algo cada vez mais raro e dificil, ao que parece, hoje em dia - com a nossa própria subjetividade. (GIANNETTI, 1998).

Há espaço para artigos nas ciências sociais e humanas, mas eles ainda ocupam menor escala. Isso se manifesta na comparação

Movimento, Porto Alegre, v.12, n. 03, p. 193-225, setembro/dezembro de 2006. 
das dimensões da base de dados do Institute of Scientific Information (ISI) para as Artes, Humanidades e Ciências Sociais em relação à base para as Ciências Naturais. Vale destacar que a análise da referida base para as Ciências Sociais denota predomínio de periódicos de áreas com forte inclinação para aspectos quantitativos e experimentais como Psiquiatria, Psicologia Comportamental, Economia, Administração, etc (GIANNETTI, 1998). Outro aspecto a ser ressaltado é o de que a análise de artigos publicados em periódicos das sub-áreas sóciocultural e pedagógica da Área 21 apresentam uma média de 90\% de citações em livros. $\mathrm{O}$ artigo, portanto, nessas sub-áreas, propicia visibilidade mais rápida a algum assunto e, ao mesmo tempo, remete o leitor aos livros e capítulos como principais fontes na discussão e reflexão a respeito dos temas abordados.

Nas ciências sociais e humanas encontramos várias áreas orientadas para a intervenção: Economia, Administração, Pedagogia, Educação Física, Saúde Coletiva, Enfermagem, Terapia Ocupacional, podem ser exemplos, e a produção que resulta desses saberes e práticas provocaram outros modos de veicular o conhecimento: as políticas, as ações, e os programas de forma a privilegiar a dimensão social, os interesses, necessidades e desejos da sociedade 6 . E é importante lembrar aqui que esse tipo de produção guarda correspondência com as patentes, mencionadas anteriormente.

\section{OS LIMITES DOS INDICADORES BIBLIOMÉTRICOS}

Nas duas últimas décadas foram realizados rankings de universidades como uma forma de mapear as instituições de excelência. Para Steiner (2006), as controvérsias que resultam desse tipo de iniciativa se devem às dificuldades para definir excelência

${ }^{6}$ Recomendamos aqui a leitura do livro $\mathbf{A}$ sociedade contra o social, de Renato Janine Ribeiro.

Movimento, Porto Alegre, v.12, n. 03, p. 193-225, setembro/dezembro de 2006. 
num ambiente de tanta diversidade, como combinar Artes e Humanidades com Ciências Naturais, ou ainda como equilibrar ciências fundamentais ou puras com as aplicadas (STEINER, 2006) Outro conflito é que os gestores das universidades e agências de fomento passaram a utilizar indicadores bibliométricos desconsiderando ou ignorando suas peculiaridades e limitações na avaliação da qualidade das atividades acadêmicas. (RAAN, 2005).

No caso do sistema nacional de pós-graduação, o QUALIS inicialmente era um instrumento para auxiliar na qualificação da produção intelectual, mas se tornou o guia para a avaliação dessa produção. Assim é que o artigo em periódico se transformou em ícone para a comunidade permanentemente sob avaliação.

Como vimos, há áreas em que a relação entre artigo e produção intelectual é estreita, entretanto há outras em que a produção é diversa e se distancia do artigo e essa diferença exige cada vez mais das comunidades científicas empenho na formulação de uma avaliação que contemple essa diversidade. Se, de um lado, o QUALIS contribuiu para com o processo de avaliação, de outro, ele, aos poucos e gradativamente, modela e impõe, por meio de normas, uma adequação a esse modelo e assim consegue inibir a disseminação da capacidade inventiva e criativa daqueles pesquisadores que não "cumprem" com as regras.

Na definição de um QUALIS para outras formas de produção intelectual, muitos se espelham na lógica do QUALIS periódico de modo a gerar alguns problemas. O principal deles se refere à busca de indicadores à semelhança dos que são usados no QUALIS periódicos. Tais indicadores se prestam à normalização dos periódicos, mas, são limitados para qualificar a produção intelectual, qualificação no sentido que interessa à pós-graduação.

Eugene Garfield (1983a), mentor intelectual do fator de impacto, já chamava a atenção da comunidade em 1983 para os limites do uso desses indicadores para avaliar qualidade da atividade acadêmica. Garfield (1983b) destaca que o fator de impacto é um

Movimento, Porto Alegre, v.12, n. 03, p. 193-225, setembro/dezembro de 2006. 
indicador suscetível a particularidades das áreas com tradições diversas. Por exemplo, áreas como Bioquímica tendem sempre a ter um fator de impacto muito maior que o de áreas como Matemática ou Sociologia e o motivo não é a dimensão da área ou da comunidade envolvida, mas o número de referências que cada artigo contém (quanto maior o número de referências, maior o fator de impacto) e a idade dos artigos citados (quanto mais recentes forem os artigos citados, maior o fator de impacto) (GARFIELD, 1994). Outro aspecto ressaltado por esse autor é o de que não basta contabilizar quantas vezes um artigo é citado, é fundamental que se considere porque ele é citado. Ou seja, o uso dos indicadores bibliométricos necessitaria ser complementado com análises qualitativas do contexto e do conteúdo das citações.

Os indicadores bibliométricos apresentam problemas conceituais e metodológicos, constituindo apenas um indicador parcial e de primeira aproximação à atividade científica que se pretende avaliar. No que se refere aos problemas conceituais, a problemática advém da interação informal que permeia a ciência, que abrange desde redes pessoais de cientistas até as comunicações científicas formais, passando pela chamada produção de "literatura cinzenta" ${ }^{\prime 7}$ e pelos novos canais das tecnologia de informação e de comunicação.

As dificuldades metodológicas se concentram na construção das bases de dados surgidas com intuito de divulgar a ciência, delas derivando indicadores de produtividade da ciência (web of science) ou de outras bases que têm vocação canalizada para a gestão utilizadas como ferramenta de pesquisa ( $C V$-Lattes). Nessa dimensão, além do que mencionamos anteriormente, Coryn (2005) faz uma lista de questões que colocam em cheque o uso desses indicadores, do ponto de vista prático e técnico: a) livros

7"Literatura cinzenta": o termo grey literature foi cunhado por bibliotecários ingleses, em um evento de Biblioteconomia, 1978, na cidade de York, popularizando-se na década de 1980. Relatórios, teses, trabalhos de eventos, pré-publicações, publicações oficiais, traduções, patentes, normas, atas, manuais técnicos, literatura comercial, entre outros, são exemplos.

Movimento, Porto Alegre, v.12, n. 03, p. 193-225, setembro/dezembro de 2006. 
não são incluídos nas bases de dados ISI como fonte de citações; b) autores que trabalham em disciplinas emergentes ou não tradicionais tendem a ser menos citados ou raramente citados; c) trabalhos são citados sem que se tenha certeza que de fato foram lidos; d) ausência de controle sobre as auto-citações; e) trabalhos inovadores, à frente de seu tempo, tendem a ser menos citados; f) as bases de dados ISI são dominadas por publicações norte-americanas; g) a língua em que o trabalho é escrito determina a freqüência de citações; h) há um alto grau de erros na base de dados ISI e um considerável grau de arbitrariedade na seleção de referências que um autor cita; i) e, autores que apresentam grande quantidade de artigos em periódicos de impacto mas que são pouco citados em contraste com aqueles que escrevem poucos artigos mas cuja freqüência de citação é alta.

Em suma, os aspectos conceituais e metodológicos dos indicadores se, de um lado, melhoram o nível de agregação do conhecimento, de outro podem ocultar diferenças importantes e misturar produções diversas e incomparáveis entre áreas e subáreas. Nesse sentido, a transformação de dados secundários, como é o caso dos índices bibliométricos, em instrumentos de avaliação da produção científica é, no mínimo, complexa e problemática.

\section{AS BASES DE DADOS}

O mapeamento da produção científica realizado via coleta e tratamento de dados pelo Thomson e Institute for Scientific Information (ISI) se tornou o modelo a ser seguido quando se fala em avaliação de desempenho acadêmico seja de indivíduos, grupos de estudo e instituições de pesquisa e ensino. Ainda que haja reconhecida correlação entre atividade acadêmica e impacto de periódicos científicos e freqüência de citações, peritos em informação científica são os primeiros a destacar os perigos de uma associação linear entre esses elementos (GARFIELD, 1994). Em síntese, a avaliação do desempenho acadêmico não pode dispensar a análise do produto intelectual em si, seja ele um artigo em

Movimento, Porto Alegre, v.12, n. 03, p. 193-225, setembro/dezembro de 2006. 
periódico científico, um livro ou capítulo de livro, ou uma patente, entre outros exemplos.

O ISI tem como principais produtos as bases de dados que compilam referências bibliográficas divulgadas em periódicos científicos que cobrem todas as áreas do conhecimento. Hoje, estima-se que circulem pelo mundo, cerca de um milhão de periódicos científicos. Menos de 1\%, aproximadamente nove mil, encontra-se indexado no ISI, em três bases de dados: 1. SCI (Science Citation Index), cobre a maioria das revistas internacionais para as áreas da Ciências básicas, aplicadas e médicas e indexa em torno de seis mil dos principais periódicos referentes a 184 áreas das chamadas Ciências Nomotéticas ${ }^{8}$. Sua velocidade de atualização gira em torno de 18 mil novos artigos por semana; 2 . No campo das Ciências Humanas e Sociais, o ISI oferece o SSCI (Social Science Citation Index) com aproximadamente 1.800 periódicos que abrangem 50 áreas do conhecimento; 3. Nas Artes e Humanidades há o AHCJ (Art \& Humanities Citation Journal) que relaciona por volta de 1.200 periódicos, indexando aproximadamente 2.500 novos artigos semanais.

A representatividade da base $S C I$ é pouco contestada pela comunidade por ser completa e aprofundada e estar muito próxima da necessidade dos cientistas dessas áreas, o mesmo não ocorre com a base SSCI composta por disciplinas sociais, que, por sua natureza, são menos internacionalizadas. Além das bases de dados, há uma série de publicações que tem como objeto os dados compilados por todas elas. São publicações periódicas como é especificado a seguir: A revista Journal Citation Reports - avaliação crítica das revistas mais importantes do mundo; O boletim ISI Highly Cited, lista 4.800 pesquisadores mais influentes, extraídos de uma comunidade global de aproximadamente cinco mi-

${ }^{8}$ Ciências nomotéticas são caracterizadas pelo uso de metodologia experimental e buscam sempre extrair comportamentos de tendência central de uma dada amostra.

Movimento, Porto Alegre, v.12, n. 03, p. 193-225, setembro/dezembro de 2006. 
lhões de cientistas, cobre as Ciências Nomotéticas; Scientometrics interpreta toda os dados compilados pelo ISI. Seus artigos apontam para os novos rumos da produção científica e sugerem possíveis caminhos para alcançar uma produtividade ideal.

Uma das características das bases de dados é a de dar visibilidade aos periódicos. Nos últimos anos, a Fundação de Amparo à Pesquisa do Estado de São Paulo (FAPESP) preocupada em contribuir para a internacionalização dos periódicos nacionais forjou uma base de dados nacional, o chamado Projeto SciELO (Scientific Eletronic Library Online). Trata-se de uma biblioteca virtual que disponibiliza hoje, aproximadamente, 200 periódicos científicos brasileiros relacionados a sete áreas: Ciências Agrícolas, Biológicas, Química, Engenharia, Geociências, Ciências da Saúde e Ciências Humanas. A intenção é dar condições para que periódicos nacionais sejam representados de forma mais marcante nas diferentes bases gerenciadas pelo ISI.

O Brasil, todavia, tem poucas revistas indexadas pelo ISI, aproximadamente 30 títulos. Nesse sentido, o crescimento científico do país a partir da inclusão de periódicos brasileiros nesse banco de dados, não condiz com a produção nacional. Usando da base de dados do ISI, David King analisou a produção científica em periódicos de 31 países, incluindo o Brasil, que respondem por cerca de $98 \%$ dos artigos mais citados, nos últimos dez anos. Na análise, o Brasil, único representante da América Latina considerado nesse estudo, aparece em 24 lugar (King, 2004, p.267) .

Nos últimos anos, as agências de fomento federais, em particular CAPES e CNPq, assim como as universidades têm demonstrado especial predileção por contabilizar a presença de trabalhos nacionais publicados em periódicos de impacto, isto é, periódicos nas bases de dados ISI. Esse tem sido o parâmetro para registrar a evolução da ciência brasileira. Se é inegável que a participação nacional tem aumentado em periódicos de impacto, ainda não é claro em que medida esses números traduzem a qualidade da ati-

Movimento, Porto Alegre, v.12, n. 03, p. 193-225, setembro/dezembro de 2006. 
vidade científica. $\mathrm{O}$ fato de um artigo ser publicado em periódico de impacto, não significa que ele seja um artigo de impacto. Ainda que pareça lógico pensar que um artigo numa revista com alto fator de impacto será ele também de impacto, os dados não comprovam essa dedução (GARFIELD, 1994).

\section{CABE DESTACAR:}

As bases de dados, em sua maioria, apresentam um viés em benefício dos periódicos e não de outras formas de publicação, fazendo com que a ciência dos países periféricos, em geral, e particularmente as Ciências Humanas e Sociais desses países, permaneçam duplamente sub-representadas, à medida que 95\% dos periódicos neles indexados são em língua inglesa e produzidos por instituições norte-americanas. Periódicos de países que não são de língua inglesa e estão nas bases de dados do ISI tendem a ter fatores de impacto significativamente menores (ao redor de 1.0) (GARFIELD, 1983c). Esses números, entretanto, nada têm a ver com a qualidade acadêmica dos periódicos pois fenômeno semelhante acontece com periódicos de países de "Primeiro Mundo" como a França. Trata-se de um fenômeno referente a acessos e citações que um artigo ou periódico recebe. A questão da visibilidade proporcionada pelas bases de dados ISI não se traduz necessariamente em visibilidade de periódicos de maior qualidade. Ainda que o número de periódicos nessas bases estejam na casa dos milhares é pequena a porcentagem deles (em torno de 5\%) que concentra os maiores fatores de impacto ou as maiores freqüências de citações.

A partir desses dados podemos fazer alguns questionamentos. A inserção de periódicos nacionais nas bases de dados ISI não é em si problemática, a controvérsia reside no que poderíamos chamar de atração (fatal) para as bases de dados do ISI (RAAN, 2005), ou seja, os editores trabalham no sentido de normalizarem seus periódicos com o fim de atender aos critérios bibliométricos exigidos para inserção nas bases, independentemente se nesse pro-

Movimento, Porto Alegre, v.12, n. 03, p. 193-225, setembro/dezembro de 2006. 
cesso a qualidade e a diversidade acadêmica da produção estão contempladas.

Há quem defenda a idéia de que há no Brasil uma profusão de periódicos e que cada área deveria investir num número reduzido deles e assim direcionarem melhor os esforços para normalizálos e levá-los às diferentes bases de dados internacionais. Entretanto, para essa discussão é fundamental compreender o processo de criação, desenvolvimento e morte dos periódicos, como bem destaca Neto e Nascimento (2002), pois do contrário estaríamos delimitando sem contextualizar.

A quantidade e a diversidade de periódicos nacionais deve ser objeto de análise para se entender a natureza da produção nacional nesse veículo. Todavia, a "atração" pelas bases de dados do ISI faz com que essa diversidade de produção seja sufocada, posto que atualmente a grande maioria dos pesquisadores tem evitado publicar em periódicos que não sejam indexados nas bases de dados consideradas no QUALIS da área.

As tradições e culturas de cada campo também desempenham papel preponderante nesse processo. As áreas ligadas às ciências naturais têm maior tendência a buscarem a indexação nas bases ISI. Outras áreas, como a das Ciências Humanas e Sociais, são menos atraídas por essas bases. Assim, a maior parte dos artigos de pesquisadores brasileiros são publicados em periódicos que não se preocupam com as bases ISI.Lembrando da produção cujo meio de veiculação não privilegia o periódico, mas o livro, vale perguntar: para as comunidades nacional, regional e local qual artigo traz maior contribuição, aquele que é publicado numa revista ISI com fator de impacto 3.0, mas que nunca é citado por outros, ou aquele que é veiculado numa revista nacional lida por centenas de acadêmicos, profissionais e estudantes?

Outro ponto é considerar a vocação de cada área e o veículo de comunicação mais adequado para que tenha efetivo impacto junto à comunidade. Ao invés de se estabelecer de forma arbitrá-

Movimento, Porto Alegre, v.12, n. 03, p. 193-225, setembro/dezembro de 2006. 
ria qual é esse veículo, seria desejável que os órgãos gestores da pesquisa e da pós-graduação delegassem à comunidade científica a responsabilidade pela decisão da produção que ela julga meritória na avaliação da qualidade de sua produtividade.

A “atração" para a base ISI criou o mito de que a única forma de dar visibilidade aos resultados de pesquisas desenvolvidas nos países periféricos reside na procura de periódicos indexados pelo ISI. Seria preciso considerar o significado dessa visibilidade. Ela não é passaporte seguro para a excelência acadêmica, se assim fosse a ciência brasileira não teria tido a evolução que teve nos últimos cinqüenta anos, posto que a ênfase em valorizar apenas o que é publicado em periódicos da base ISI é um fenômeno relativamente recente, de 1995 para cá.

Essa opção tem causado um grande prejuízo para os periódicos nacionais e em particular às Ciências Humanas e Sociais desenvolvidas no Brasil. Dos aspectos negativos dessa política podemos destacar: 1. a ameaça a existência das publicações locais posto que recursos financeiros das agências de fomento que poderiam sustentá-las são desviados para dar apoio à publicação em periódicos internacionais da base ISI, considerando que muitos desses periódicos só publicam mediante pagamento; 2. o abandono do português em favor de outras línguas, causando prejuízos incalculáveis às Ciências Humanas e Sociais; 3. e, a prática de publicar em periódicos pode provocar um reducionismo das comunicações efetuadas, uma vez que as revistas incluem em seus critérios de publicação uma séria restrição ao número de páginas, prática incoerente com as demandas de divulgação científica das áreas sociocultural e pedagógica.

O uso de bases indexadores como critério para julgar a qualidade do material publicado tem limites importantes. Como já colocamos, publicar um artigo num periódico de alto fator de impacto não é sinônimo de alto impacto do artigo em si. O fator de impacto não é indicativo da qualidade acadêmica do trabalho, para se julgar essa

Movimento, Porto Alegre, v.12, n. 03, p. 193-225, setembro/dezembro de 2006. 
qualidade seria necessário avaliar em profundidade o artigo em si.

O equivalente a base de dados para os livros apresenta uma característica diversa. Há, por exemplo, o Book Review Index Plus (BRIP) encontrado no sítio da Library Universities, hospedado na University of Maryland, o BRIP traz em meio eletrônico resenhas e revisões de livros acadêmicos e profissionais disponíveis desde de 1965. Trata-se da apreciação do valor acadêmico e profissional de livros publicados. A avaliação, assim, é sobre o livro produzido. A seguir, disponibilizamos outras bases ${ }^{9}$ similares: Combined Retrospective Index to Book Reviews in Scholarly Journals. Indexação de resenhas de livros publicadas em 459 periódicos acadêmicos de história, ciência política e sociologia; Current Book Review Citations. Compilação de autor/título de todas revisões indexadas em outras bases de Wilson assim como revisões que apareceram em publicações de outras bases. São cobertos cerca de mil periódicos; Guia a las Resenas de Libros de y sobre Hispanoamerica. A Guide to Reviews of Books from and About Hispanic America. Inclui o sumário de resenhas em inglês e espanhol em mais de 570 periódicos; Internationale Bibliographie der Rezensionen Wissenschaftlicher Literatur. Bibliografia internacional de resenhas de livros acadêmicos.

Em todos esses casos, vale citar, o que se julga é o livro em si em termos de seu mérito acadêmico para uma área, um tema ou problema em particular. Infelizmente, essas bases e outras bases são ignoradas pelo ISI, o que torna questionável a postura desse instituto no que diz respeito a mapear a produção científica mundial. A iniciativa brasileira de disponibilizar várias bases de dados do porte do $C V$-Lattes, da Lista Qualis, da Biblioteca Digital de Teses e Dissertações, do Portal de Periódicos, o SciELO é sem dúvida louvável, mas sofre dos mesmos equívocos apontados para as bases de dados ISI.

${ }^{9}$ Fonte: University of Maryland, http://researchport.umd.edu

Movimento, Porto Alegre, v.12, n. 03, p. 193-225, setembro/dezembro de 2006. 


\section{O IMPACTO DA PRODUÇÃO INTELECTUAL}

Em termos gerais, os resultados de impacto da pesquisa costumam ser avaliados por meio da mensuração de artigos publicados em periódicos científicos e, conseqüentemente, o desempenho das Ciências Nomotéticas ao utilizar indicadores quantitativos dos artigos e suas variantes é muito bom já que considera: a auto-citação, a co-citação (citação em grupos), os periódicos em que foram publicados, os dados de fator do impacto estimado dessas publicações, as patentes, as inovações tecnológicas e o incremento de produtividade das empresas como elementos utilizados para medir a produtividade.

Nas Ciências Humanas e Sociais, os periódicos e artigos constituem apenas um dos meios possíveis para se medir a produtividade científica. Os periódicos se prestam muito mais à divulgação de resultados de pesquisas parciais, ou em andamento. Outras modalidades de produção: livros e suas variantes, capítulos, coletâneas e o trabalho de coordenação editorial de uma série, eventos, pareceres, relatórios, laudos, resenhas, organização de filmes e divulgação na mídia - "literatura cinzenta" - que raramente são considerados pelos consagrados indicadores internacionais, prejudicam a avaliação de desempenho das áreas e subáreas, inclusive no que se refere à obtenção de recursos.

Além da forma estreita com que a produção é considerada, o conceito de impacto é envolto em mitos e equívocos. Se o pesquisador cita um artigo significa que esse trabalho lhe pareceu de alguma forma relevante. Nesse sentido, pode-se dizer que o artigo teve impacto em outro trabalho. Todavia, não há um número que expresse se isso de fato ocorreu ou não. O fator de impacto tão utilizado e mencionado pela comunidade científica para qualificar ou desqualificar uma produção nada diz a respeito dessa questão. Se não houver uma análise do contexto e do conteúdo das citações o real impacto do artigo não poderá ser apreciado. Essa é uma orientação dada pelos próprios cientistas da informação, versados na bibliometria.

Movimento, Porto Alegre, v.12, n. 03, p. 193-225, setembro/dezembro de 2006. 
Outra referência para a noção de impacto em pós-graduação pode ser obtida a partir das atividades de formação desenvolvidas pelos estudantes de mestrado e doutorado. O sistema nacional de pós-graduação atribui grande peso à participação do estudante nas disciplinas, pois, teoricamente, elas desenvolvem papel formador à medida que orientam nas diferentes linhas de pesquisa do programa e nos temas relevantes para a pós-graduação.

O programa das disciplinas inclui bibliografia para que o aluno possa desenvolver os temas a serem discutidos ao longo do curso. Diferentemente do fator de impacto calculado para os periódicos, a citação de autores na bibliografia pode ser um indicativo do papel formador que esses autores exercem. Recentemente fizemos um levantamento das citações na bibliografia das disciplinas de treze programas da sub-área Educação Física no triênio 20012003 e 2004. As citações relativas ao pesquisador em disciplinas nas quais ele é docente não foram computadas.

A Tabela 1 apresenta o índice de citações em programas distinguindo entre docentes das sub-áreas sóciocultural e pedagógica, psicológica e biodinâmica. Estabelecemos que seriam considerados os docentes que fossem citados em pelo menos três programas. Assim, chegamos a quatro faixas de citação, em três, quatro, cinco e seis programas da área. Com essas faixas identificamos trinta docentes.

TABELA 1 - FREQÜÊNCIA DE CITAÇÕES EM PROGRAMAS DE DOCENTES POR SUB-ÁREA - ÁREA EDUCAÇÃO FÍSICA - PERÍODO 2001-2004

\begin{tabular}{|c|c|c|c|c|}
\hline $\begin{array}{c}\mathbf{N}^{\circ} \text {. de programas } \\
\text { em que od docente é é } \\
\text { citado }\end{array}$ & $\begin{array}{c}\mathbf{N}^{\circ} \text {. de docentes da } \\
\text { sub-área } \\
\text { Biodinâmica }\end{array}$ & $\begin{array}{c}\mathbf{N}^{\circ} \text {. de docentes na } \\
\text { sub-área } \\
\text { Psicológica }\end{array}$ & $\begin{array}{c}\mathbf{N}^{\circ} \text {. de docentes nas sub- } \\
\text { áreas Sóciocultural e } \\
\text { Pedagógica }\end{array}$ & $\begin{array}{c}\text { Total de } \\
\text { docentes }\end{array}$ \\
\hline 6 & - & 1 & 4 & 5 \\
\hline 5 & 1 & 1 & 4 & 6 \\
\hline 4 & 2 & 1 & 3 & 6 \\
\hline 3 & 6 & 1 & 6 & 13 \\
\hline Total & $\mathbf{9}$ & $\mathbf{4}$ & $\mathbf{1 7}$ & $\mathbf{3 0}$ \\
\hline
\end{tabular}

Movimento, Porto Alegre, v.12, n. 03, p. 193-225, setembro/dezembro de 2006. 
O maior índice de citações foi seis programas, isto é, um docente teve sua produção referenciada em no máximo seis programas da área de Educação Física. Nessa faixa, encontramos cinco docentes dos quais quatro pertencem às sub-áreas sociocultural e pedagógica e um é da sub-área psicológica. Todas as produções referenciadas nessa faixa foram livros ou capítulos de livros. Na faixa seguinte, com citação em cinco programas, encontramos seis docentes, novamente com maioria para as sub-áreas sóciocultural e pedagógica (quatro), mais um docente para cada sub-área, psicológica e biodinâmica. Nas outras faixas predominam docentes das sub-áreas sociocultural e pedagógica em relação às outras duas sub-áreas da Educação Física. Dos trintas docentes mais citados, dezessete são da sóciocultural e pedagógica, quatro da psicológica e nove da biodinâmica. Há amplo predomínio de citações em livros ou capítulos de livro. As citações em artigos quando ocorreram foram no nível Internacional C e Nacional B ou C. Não houve qualquer citação referente a artigo publicado em periódicos da base ISI.

As sub-áreas sóciocultural e pedagógica demonstram alto impacto na pós-graduação na área de Educação Física embora elas têm padecido nas avaliações da CAPES devido à dificuldade em atender os critérios de produção estabelecidos pela Grande Área da Saúde. Em síntese, há claro descompasso entre o que a área reputa como produção de impacto e o que é considerado como indicador de produção de qualidade pelos gestores da avaliação na CAPES.

8. OS TEMAS DAS CIÊNCIAS HUMANAS E SOCIAIS NA GRANDE ÁREA DA SAÚDE

A área de saúde esteve sempre associada às ciências naturais. Todavia, especialmente nas últimas quatro décadas a aproximação entre saúde e ciências sociais e humanas significou grandes mudanças ${ }^{10}$. Dessa aproximação também decorre

${ }^{10} \mathrm{Há}$ vários autores no campo da saúde que se dedicam a esse tema, Ana Maria Canesqui, Everardo Duarte Nunes e Madel Terezinha Luz podem ser exemplos.

Movimento, Porto Alegre, v.12, n. 03, p. 193-225, setembro/dezembro de 2006. 
o embate que vem de longa data e que se reproduziu e se reproduz na Grande Área da Saúde entre essas ciências (SNOW, 1995). Por essa razão vale expressar uma vez mais o que distingue uma ciência e outra:

[...]o que distingue as Ciências Sociais e Humanas das Ciências Naturais é que o objeto das primeiras está em constante transformação, enquanto a matéria física pode considerar-se invariável e a evolução orgânica se produz muito lentamente (...). As Ciências Sociais não podem ser Ciências Experimentais e Exatas em termos estritos. Não são experimentais porque a sociedade está em transformação constante e não é a mesma em dois momentos diferentes da experiência. O controle das condições de observação atenta contra a dinâmica social e as potencialidades do desenvolvimento humano. As Ciências Sociais não são exatas porque não podem determinar de antemão os efeitos da criatividade e da ação constante do homem na transformação de suas estruturas sociais. (LEFF, 1976, p. 1340).

A Área de Saúde encampa desde problemas afeitos às ciências naturais até aqueles cuja abordagem demanda uma orientação das ciências sociais e humanas. Alguns exemplos de questões consideradas locais e que tocam em temas cruciais: exploração sexual e violência (mulher, criança, adolescente). De modo geral, elas estão associadas às condições de vida cujos temas embora privilegiem o "local" têm repercussão universal. A divulgação de pesquisas sobre esses temas nem sempre vai interessar a periódicos da base ISI, mas sua divulgação local cumpre um papel social fundamental que tende a ser sufocado quando há extrema valorização para o que é publicado em periódico internacional com alto fator de impacto.

Por serem temas de repercussão universal não raro eles chamam a atenção da comunidade internacional não porque foram

Movimento, Porto Alegre, v.12, n. 03, p. 193-225, setembro/dezembro de 2006. 
publicados em periódicos ISI, mas pela qualidade do trabalho desenvolvido que, por outras vias, conquista visibilidade internacional. A "atração" para as bases ISI é talvez mais forte hoje na área da saúde, em especial no que concerne às medicinas. Recentemente, um levantamento de dados do volume de artigos publicados em periódicos ISI mostrou que pela primeira vez a física brasileira perdeu o posto de mais produtiva para as áreas médicas ${ }^{11}$.

Isto não significa que os empreendimentos para encaminhar periódicos nacionais às bases ISI são prejudicais à produção do conhecimento cuja orientação está centrada nas ciências sociais e humanas. O problema como já destacamos reside na forma estreita de se tratar e qualificar a produção. Nos últimos anos, um dos principais nós na avaliação da pós-graduação na área de saúde foi o tratamento dado ao livro, considerado como uma produção pouco relevante para a área. Se essa concepção já é equivocada independente da área, ela é ainda mais nociva para uma área que abarca tanta diversidade em termos de ciências, diversidade que é, num certo sentido, a própria riqueza da área de saúde.

As diferenças entre as ciências se manifestam inclusive se tomarmos como referências periódicos científicos. Por exemplo, as Ciências Nomotéticas apresentam artigos breves, o que reduz o custo de sua publicação e o aumento de espaço disponível nos periódicos tem superado o crescimento do número de cientistas. A revista The Physical Review aumentou 4,6 vezes em quinze anos. Entre 1950 e 1965, saltou de 3920 páginas para 17060, enquanto o número de membros cresceu somente 2,4 vezes. Já o número de páginas disponíveis na publicação da American Sociological Association permaneceu praticamente estável no mesmo período analisado, enquanto o número de membros aumentou 2,5 vezes.

A formação no campo das Ciências Humanas e Sociais exi-

${ }^{11}$ Fonte: ver a Folha de São Paulo, dados mostrados na SBPC 2006 Florianópolis;

Movimento, Porto Alegre, v.12, n. 03, p. 193-225, setembro/dezembro de 2006. 
ge longo tempo de aprendizado com vistas à transformação do estudante num pensador de primeira linha e longa experiência de pesquisa para incorporação dos fundamentos teóricos e das técnicas. São campos poucos afeitos a leis gerais, supõem a consideração da especificidade e particularidade dos fatos e fenômenos observados, exigindo o amadurecimento dos dados empíricos da bibliografia consultada e do "momento interpretativo", os quais exigem consulta a cada um dos acervos mencionados, raciocínio lento e original, cuidados lógicos finos na construção da frase e do texto como um todo.

Nos últimos anos a avaliação da pós-graduação colocava grande peso no tempo de titulação, quanto mais rápida a conclusão do curso melhor. Essa orientação entrou em choque direto com a formação no campo das ciências humanas e sociais. Felizmente, no último triênio, o tempo para titulação passou a ter importância relativa deixando para que cada área, de acordo com sua tradição e cultura, definisse o tempo ideal para uma boa formação. Carece demonstrar a mesma sensibilidade e consideração para com as especificidades das áreas no quesito produção intelectual.

No que concerne à área de saúde, é interessante nos remetermos a alguns dados compilados pelo setor de avaliação da CAPES e disponibilizado pela Diretoria de Avaliação em $2005^{12}$. A Tabela 2 apresenta a proporção de artigos, livros e capítulos de livro por docente nas áreas que compõem a Grande Área da Saúde, no triênio 2001-2003. As áreas de Enfermagem, Educação Física e Saúde Coletiva apresentam proporções de livro/docente acima da média da Grande Área de Saúde. Os programas dessas áreas apresentam várias linhas de pesquisa com orientação das ciências sociais e humanas. Já nas outras áreas, nas Medicinas, na

${ }^{12}$ Dados fornecidos pelo Prof. Renato Janine Ribeiro por ocasião de sua conferência sobre A avaliação da Pós-Graduação nas áreas de Ciências Sociais e Humanas proferida na Universidade de São Paulo, Campus da Capital, em 2005.

Movimento, Porto Alegre, v.12, n. 03, p. 193-225, setembro/dezembro de 2006. 
Odontologia e na Farmácia predomina o artigo como principal meio de veiculação da produção. Como é de domínio público, o Qualis da Grande Área é orientado aos periódicos, livros e capítulos de livro são colocados em segundo plano. Por exemplo, não se admite um docente permanente que no triênio só tenha como produção livro ou capítulo de livro. Essa é uma situação flagrante de como os indicadores determinam o que e como se produz!

TABELA 2. PERFIL DA PRODUÇÃO INTELECTUAL DAS ÁREAS DA GRANDE ÁREA DA SAÚDE TRIÊNIO 2001-2003

\begin{tabular}{l|c|c|c|c|}
$\begin{array}{l}\text { Área de } \\
\text { avaliação }\end{array}$ & $\begin{array}{c}\text { Média } \\
\text { Livro/docente }\end{array}$ & $\begin{array}{c}\text { Média Artigo } \\
\text { Internacional } \\
\text { A/docente }\end{array}$ & $\begin{array}{c}\text { Média Artigo } \\
\text { Nacional } \\
\text { A/docente }\end{array}$ & $\begin{array}{c}\text { Média } \\
\text { Capitulo/docente }\end{array}$ \\
\hline Medicina I & 0.10 & 1.29 & 0.26 & 2.01 \\
\hline Medicina II & 0.11 & 1.07 & 0.48 & 1.71 \\
\hline Medicina III & 0.15 & 0.53 & 0.63 & 3.36 \\
\hline Odontologia & 0.15 & 0.51 & 0.07 & 0.67 \\
\hline Farmácia & 0.06 & 1.35 & 0.09 & 0.50 \\
\hline Enfermagem & 0.22 & 0.06 & 0.07 & 1.17 \\
\hline $\begin{array}{l}\text { Educação } \\
\text { Fisica }\end{array}$ & 0.31 & 0.24 & 0.28 & 1.91 \\
\hline $\begin{array}{l}\text { Saúde Coletiva } \\
\text { Grande Área da } \\
\text { Saúde* }\end{array}$ & 0.24 & 1.06 & 0.11 & 1.66 \\
\hline
\end{tabular}

*Área 21 que engloba Educação Física, Fonoaudiologia, Fisioterapia e Terapia Ocupacional. ** Média das médias de todas as áreas listadas acima.

A Educação Física apresenta a maior proporção de livros/ docente denotando que para essa área a produção de livros e capítulos de livro é importante. Na Tabela 3, os dados da produção apresentada pelas sub-áreas da área 21 no ano de 2004 mostram que a Educação Física e Fonoaudiologia apresentam a maior porcentagem de livros e capítulos. Já a Fisioterapia apresenta um perfil que a aproxima mais das áreas médicas. Não há dados para a Terapia Ocupacional posto que essa área ainda não conta com um programa específico de pós-graduação.

TABELA 3 - TIPO DE PRODUÇÃO NAS ÁREAS DE EDUCAÇÃO FÍSICA, FONOAUDIOLOGIA E FISIOTERAPIA EM 2004

\begin{tabular}{|c|c|c|c|}
\hline Tipo de produção & Educação Física & Fonoaudiologia & Fisioterapia \\
\hline Livros/Capítulos & $\mathbf{3 3 . 3 7}$ & $\mathbf{3 6 . 6 1}$ & $\mathbf{2 0 . 1 5}$ \\
\hline Artigos & $\mathbf{6 6 . 7 3}$ & $\mathbf{6 3 . 3 9}$ & $\mathbf{7 9 . 8 5}$ \\
\hline
\end{tabular}

Movimento, Porto Alegre, v.12, n. 03, p. 193-225, setembro/dezembro de 2006. 
$\mathrm{Na}$ composição da produção dessas áreas os artigos predominam mas cabe ressaltar que esse é um efeito dos indicadores aplicados no Qualis da área que restringia, e que em vários casos ainda restringe, a contagem de livros a $25 \%$ do total de produção de artigos em periódicos científicos. Vários programas tiveram parte de sua produção em livros e capítulos descartados para o computo final da avaliação pelo fato da produção em artigos não ter sido grande o suficiente para incluí-los. Esse é mais um efeito nefasto da utilização de indicadores de forma incompatível com uma avaliação de qualidade da produção.

Outro dado que merece atenção refere-se à comparação do perfil da produção da área 21 em relação a algumas áreas das ciências sociais e humanas ${ }^{13}$ (Tabela 4).

TABELA4. PERFIL DA PRODUÇÃO INTELECTUAL DAS ÁREAS DE EDUCAÇÃO FÍSICA EM RELAÇÃO ÀS CIÊNCIAS SOCIAS E HUMANAS - TRIÊNIO 2001-2003

\begin{tabular}{l|c|c|c|c|}
\hline $\begin{array}{c}\text { Área de } \\
\text { avaliação }\end{array}$ & $\begin{array}{c}\text { Média de } \\
\text { Livro/docente }\end{array}$ & $\begin{array}{c}\text { Média Artigo } \\
\text { Internacional } \\
\text { A/docente }\end{array}$ & $\begin{array}{c}\text { Média Artigo } \\
\text { Nacional } \\
\text { A/docente }\end{array}$ & $\begin{array}{c}\text { Média } \\
\text { Capitulo/docente }\end{array}$ \\
\hline Filosofia/Teologia & 1.37 & 0.55 & 0.48 & 3.14 \\
\hline Direito & 1.19 & 0.02 & 0.41 & 1.56 \\
\hline História & 0.91 & 0.17 & 0.80 & 2.61 \\
\hline Educação & 0.69 & 0.21 & 0.36 & 2.48 \\
\hline Ed. Física* $^{*}$ & 0.31 & 0.24 & 0.28 & 1.9 \\
\hline
\end{tabular}

*Área 21 que engloba Educação Física, Fonoaudiologia, Fisioterapia e Terapia Ocupacional

O perfil da Educação Física se aproxima do perfil das áreas selecionadas de ciências sociais e humanas, tanto em relação aos livros como em relação aos capítulos de livro. Caso fosse computada na média da Educação Física apenas a produção da Fonoaudiologia e da Educação Física, a aproximação desse perfil ao das ciências sociais e humanas seria ainda maior.

${ }^{13}$ Ibidem.

Movimento, Porto Alegre, v.12, n. 03, p. 193-225, setembro/dezembro de 2006. 
Em síntese, os dados corroboram a idéia de que a produção de cada área tende a seguir a cultura e a tradição das ciências que as orientam. As ciências sociais e humanas têm profundo impacto na Grande Área da Saúde. Todavia, grande parte da riqueza da produção das sub-áreas que a compõem, Saúde Coletiva, Enfermagem e Educação Física, não é considerada em uma avaliação que pretende falar sobre a qualidade do que se faz na pós-graduação. Os critérios de avaliação da produção intelectual da Grande Área da Saúde devem ser homogêneos no que diz respeito ao rigor, mas isso não significa que os mesmos indicadores possam ser aplicados indistintamente a todas sub-áreas.

\section{ALGUNS DESAFIOS PARAA COMUNIDADE CIENTÍFICA}

O resgate do livro como indicador de qualidade e quantidade na produção intelectual remete a questões e temas que avançam para uma reflexão relativa à própria avaliação da ciência e da pesquisa. A avaliação do livro no âmbito da pós-graduação e da pesquisa sempre foi deixada de lado sob o pretexto de que ela era muito difícil de operacionalizá-la devido a falta de indicadores objetivos, diga-se quantitativos. A referência para essa argumentação foi o instrumental da bibliometria. No entanto, como é reconhecido pelos próprios mentores da cienciometria, o indicador quantitativo da produção em periódicos tem limitações importantes no que tange à avaliação de mérito acadêmico das produções intelectuais.

A avaliação do livro possibilita visualizar parcela importante da produção intelectual dos programas, em particular aquela referente ao conhecimento gerado nas áreas de concentração sociocultural e pedagógica. Assim, contribuirá também para que tenhamos um quadro mais realista da natureza e da qualidade da pós-graduação nacional nas fronteiras que demarca a sua diversidade.

A análise do livro fundamenta-se em uma lógica diferenci- 
ada daquela utilizada, por exemplo, no QuALIs periódico: primeiro cada livro é manuseado, aberto e consultado com intuito de caracterizar a sua natureza, se o seu conteúdo é pertinente ao formato livro e se este é representativo para a pós-graduação; segundo, um livro pode ter um tempo de elaboração e de repercussão diferente do de um artigo, pode, a depender de sua qualidade, ser considerado como produção válida por períodos mais longos do que um triênio, de modo a relativizar a quantidade de produções. Atualmente, predomina o uso de indicadores quantitativos de produção que passam ao largo da análise do conteúdo em si. A avaliação do livro se contrapõe a essa lógica e assim indica que é possível trilhar outros caminhos na avaliação da pós-graduação.

A avaliação de livros precisa ser relativa a conteúdo, as resenhas podem ser exemplos. Há outros indicadores, sem dispensar a avaliação do livro em seu próprio contexto, que podem ser desenvolvidos sem que se entre em exercícios de numerologia perdendo de vista a qualidade acadêmica desse produto. Por força de síntese os seguintes pontos deveriam ser considerados como desafios para avançarmos nas discussões trazidas aqui: a) A produção dos diferentes ramos do conhecimento deve refletir as singularidades e particularidades de cada área, a utilização sistemática de referees, de árbitros, evitando avaliações indiretas e calcadas em índices bibliométricos, baseada no método de julgamento por pares pode facilitar a avaliação dos pesquisadores uma vez que são os colegas capazes de reconhecer o estado da arte em seu campo e dar um parecer sobre a qualidade do produto; b) A avaliação é importante mas precisamos encontrar critérios similares no rigor, mas diferentes para as diversas áreas e circunstâncias históricas. É preciso gerar indicadores que permitam avaliar a comunicação dos resultados de pesquisa, respeitando a diversidade e pluralidade, que trocam semelhanças e diferenças por meio das áreas e subáreas; c) No que se refere ao fator de impacto "uma característica marcante de publicações importantes não é só o fato de serem altamente citadas, mas serem citadas durante um período

Movimento, Porto Alegre, v.12, n. 03, p. 193-225, setembro/dezembro de 2006. 
de tempo mais longo do que outras publicações" (MEADOWS, 1999, p.97); logo não se pode considerar como produção qualificada apenas aquela do triênio, mas também a que vai além desse período por conta das citações e menções a ela; d) "É notável a tendência generalizada de que os artigos de um periódico citem a outros artigos do mesmo periódico" (MERTON, 1977, p. 597), a circularidade que aí se estabelece gera alta freqüência de citações que denotam a questionável "qualidade" do periódico; e) As considerações de falta de visibilidade internacional da produção científica nacional só não são mais graves, porque escondem a própria visibilidade dessa produção em âmbito local, apesar de nossas publicações, em sua grande maioria, serem de ótima qualidade, isto é, "não é a qualidade que determina a não visibilidade" (MENEGHINI, 1998, p. 220); f) A comunicação científica no Brasil é precária devido a dificuldade de publicação oriunda da falta de recurso financeiro, de tiragens limitadas e da regionalização das publicações; g) O Qualis foi criado pela CAPES para atender às necessidades específicas da avaliação da pós-graduação no que se refere à produção bibliográfica. Todavia, sua utilização gera distorções na avaliação e incongruências num sistema que deveria aferir a qualidade da produção de forma homogênea, por exemplo, um mesmo periódico pode receber diferentes classificações quando analisado em diferentes áreas do conhecimento; e, a classificação dos periódicos em A/B internacional é obtida, em grande parte, pelos comitês de avaliação de áreas, considerando o fator de impacto medido através do Journal of Citation Reports $(J C R)$. Por estas razões os periódicos das Ciências Humanas e Sociais dificilmente integrarão o universo das revistas internacionais, porque são raros os títulos brasileiros indexados pelo ISI; h) Os livros exigem mais tempo para serem escritos como também se espera deles um maior tempo de vida útil já que a avaliação pelos pares ressurge depois da publicação. Os artigos raramente estão sujeitos a uma nova crítica; os livros científicos, ao contrário, são comumente reavaliados; i) E, é preciso estar atento para o fato de 
que os indicadores de resultados refletem apenas parcialmente os resultados, eles podem subsidiar as decisões, mas não determiná-las.

Cabe destacar, finalmente, que há muitas resistências a respeito desta discussão mas são resistências que encontram respaldo na política científica esterilizante que norteia ainda hoje os caminhos do corpo discente e docente vinculados aos programas de pós-graduação. Neste sentido, este artigo só poderia ser endereçado àqueles atentos às polêmicas relativas à pós-graduação no Brasil e protagonistas dos novos rumos que se abrem para a Grande Área da Saúde e, em especial, para a Educação Física brasileira.

Going beyond the indicators for the evaluation of the intelectual production in the big area of health Abstract: This paper presents some views we have been developing about the indicators of the intellectual production of the Brazilian scientific community, among them we have paid particular attention to books. As researchers from postgraduate programs in Physical Education, in Area 21 from the Big Area of Health, we have privileged the debate on the indicators' features, limits and possibilities for a qualitative appreciation of the intellectual production in particular for those being published in the Social and Human Sciences in the field of health, in this case, the socio-cultural and pedagogical sub-fields of Physical Education. Keywords: Scientific publication indicators. Books. Research Performance Evaluation Systems. Bibliometrics.

Movimento, Porto Alegre, v.12, n. 03, p. 193-225, setembro/dezembro de 2006. 
Para além de los indicadores de la evaluación de la producción intelectual en la gran área de la salud

Resumen: En el presente trabajo presentamos algunas reflexiones que hemos hecho sobre los indicadores de la producción intelectual de la comunidad científica brasileña con atención para el libro. Nosotros como pesquisadotes participantes de programas de postgrado en Educación Física, Area 21 de la Gran Area de la Salud, nosotros enfocamos la discusión acerca de las características, limites y posibilidad de los indicadores para una apreciación cualitativa de la producción intelectual, en particular aqueja difundida en las Ciencias Sociales y Humanas en el campo de la salud, especialmente de las subáreas sociocultural y pedagógica de la Educación Física.

Palabras clave: Indicadores de producción científica. Libros. Sistemas de creditos y evaluación de investigadores. Bibliometría.

\section{REFERÊNCIAS}

BONINI, A. Qualis de Letras/Lingüística: Uma análise de seus fundamentos. Revista Brasileira de Pós-Graduação, v.1, n.2, p. 141-159, 2004.

CHRISTENSON, J.; SIGELMAN, L. Accrediting knowledge: Journal stature and citation impact in social science. Social Science Quarterly, v.66, n.4, 1985.

CORYN, C. L. The use and abuse of citations as indicators of research quality. Journal of Multidisciplinary Evaluation, v. 4, p. 115-121, 2005.

GARFIELD, E. Analisis cuantativo de la literatura cientifica y sus repercussiones en la formulación de políticas científicas en America Latina y Caribe. Boletín de la Oficina Sanitaria Panamericana, v. 118, n.5, p. 448-456, 1995.

GARFIELD, E. Dispelling a few common myths about journal citation impacts. The Scientist, v. 11, n. 3, p.11, 1994.

GARFIELD, E. How to use citation analysis for faculty evaluations and when it is relevant. Part 1. Essays of an information scientist, v. 6, p. 354-362, 1983a.,

GARFIELD, E. How to use citation analysis for faculty evaluations and when it is relevant. Part 2. Essays of an information scientist, v. 6, p. 363-372, 1983b.

Movimento, Porto Alegre, v.12, n. 03, p. 193-225, setembro/dezembro de 2006. 
GARFIELD, E. Mapping science in the Third World - Part I. Essays of an information scientist, v.6, p.254.1983c.

GIANNETTI, E. Auto-engano. São Paulo: Cia. das Letras, 1998.

KING, D. A. The scientific impact of nations: what different countries get for their research spending. Nature, v.403, p.311-316, 2004

LEFF, E. El sistema de ciencia y tecnología en el proceso de desarrollo socioeconómico. Comercio Exterior, v. 26, n. 11, p. 1334-1341,1976.

MEADOWS, A. A comunicação científica. Brasília: Briquet de Lemos, 1999.

MENEGHINI, R. A avaliação da produção científica e projeto SciELO. Ciência da Informação, v.27, n.2, 1998;

MERTON, R. K. Os imperativos institucionais da ciência. In: DEUS, J. D. (Org.). A crítica da ciência. Rio de Janeiro: Zahar, 1979. v.2, p. 37-52.

MERTON, R. La sociologia de la ciencia: investigaciones teóricas y empíricas. Madri: Alianza, 1977. v.2.

NETO, A. F.; NASCIMENTO, A. C. S. Periódicos científicos da educação física: Proposta de avaliação. Movimento, v.8, n.2, p.35-50, 2002.

OPTHOF, T. Sense and nonsense about the impact factor. Cardiovascular Research, v. 33, p. 1-7,1997.

PRICE, D. de SOLLA. A ciência desde a Babilônia. Belo Horizonte: Itatiaia; São Paulo: EDUSP, 1976.

PRICE, D. de SOLLA. Little science, big science and beyond. New York: Columbia University, 1986

RAAN, A.F.J. van. Fatal attraction: conceptual and methodological problems in the ranking of universities by bibliometrics methods. Scientometrics, v. 62, n.1, p.133143, 2005.

SNOW, C.P. As duas culturas: uma nova leitura. São Paulo: EDUSP, 1995.

SOUZA, E. P.; PAULA, M. C. S. Qualis: a base de qualificação dos periódicos científicos utilizada na avaliação CAPES. Infocapes, Brasília, v. 10, n.2, abr./jun 2002.

STEINER, J. World university rankings: a principal component analysis. Disponível em: <http://www.iea.usp.br/iea/ensinosuperior/artigosteiner>. Acesso em: 2006.

Movimento, Porto Alegre, v.12, n. 03, p. 193-225, setembro/dezembro de 2006. 